Article

\title{
Households' Perception of Financial Incentives in Endorsing Sustainable Waste Recycling in Nigeria
}

\author{
Beatrice Abila \\ Department of Industrial Management, Faculty of Technology, University of Vaasa, P.O. Box 700, \\ 65101 Vaasa, Finland; bobule@uva.fi
}

Received: 13 March 2018; Accepted: 31 May 2018; Published: 13 June 2018

\begin{abstract}
Recycling is viewed as a central aspect in sustainability and mainly as pro-environmental consumer behavior. The purpose of this study is to examine the perception of households on financial incentives in endorsing sustainable recycling for municipal solid waste in Nigeria. The study was conducted in the Shomolu Local Government Area, Lagos State, Nigeria. The study also covers drivers for household willingness to recycle municipal solid waste on environmental risk, behavioral economics, resource value, economic benefit, convenience, knowledge, legislation, and belief. The result from the study asserts the hypothesis that financial incentives for recycling are vital for reducing and managing municipal solid waste sustainably. The most important driver for household willingness to recycle municipal solid waste is the detrimental environmental impacts. A moderate to positive relationship exists between households' perception of financial incentives for recycling and drivers for household willingness to recycle municipal solid waste. The study recommends adopting the extended producer responsibility (EPR) model, reverse vending options, amongst other approaches, in an effort to promote recycling culture among citizens and residents in Nigeria.
\end{abstract}

Keywords: solid waste management; recycling; financial incentives; behavior change; Nigeria

\section{Introduction}

The goals of waste management cannot be separated from those of sustainable development. This is because the principles of sustainable development aim to achieve economic development, social development, and environmental protection. The perpetually increasing flow of household waste is an enormous environmental issue [1]; however, social and economic issues cannot be discounted. Recycling, a sustainable strategy in addressing these problems, reduces the amount of waste directly disposed of in landfills, and has the potential to reduce disposal costs and waste transport costs. It prolongs the life span of landfill sites [2], and reduces the energy costs associated with the use of non-virgin materials during production [3], as well as ensuring the conservation of virgin materials. In other words, the effective management of waste has major potential benefits to society [4], the economy, and the environment.

Waste composition analyses suggest that over two-thirds of household waste can be recycled or composted [5]. Furthermore, findings [6] from a study on solid waste generation and characterization in the University of Lagos revealed that the recyclable potential of waste is very high, constituting about $75 \%$ of the total waste generated. Despite this, an investigation conducted in Nigeria, by the Lagos state Waste Management Authority on residents of Lagos Island revealed that about $89.0 \%$ of the respondents were aware of waste recycling, but only $47.8 \%$ were devoted to recycling [7]. Waste management with source segregation is more likely to succeed through using financial incentives to induce behavioral change than by engaging in efforts to strengthen social norms [1]. There is a possibility for increasing the number of individuals who are devoted to recycling at household level when intrinsic and extrinsic factors required for proper waste management are met. These intrinsic and extrinsic factors are 
aligned to different aspects of socio-psychology, technology, policy and legislation, as well as the economy [8]. These intrinsic factors are socio-psychological motivation factors such as moral or social norms (belief in the benefit of recycling), environmental concerns, and behavioral economics (culture of stewardship, conservation and preservation as well as resource value), while extrinsic factors include financial incentives and other convenience factors [9]. These intrinsic factors are motivations that are internally generated within the individual through passion, personal satisfaction, and self-determination. Conversely, the extrinsic factors are motivations that arise from outside the individual through rewards, obligations, and/or demands. This paper examines the perceived importance of financial incentives versus other behavioral change drivers in the adoption of sustainable recycling for municipal solid waste in Lagos state, Nigeria.

This paper includes four subsequent sections: Section 2 reviews the literature on recycling and solid waste management in Nigeria; Section 3 discusses the materials and methods applied in the study; Section 4 presents the results and discussion; and finally, Section 5 highlights the conclusion and recommendations from the study.

\section{Recycling and Solid Waste Management in Nigeria}

Nigeria typifies the many developing countries that have done less in implementing sustainable solid waste management due to the numerous barriers impeding municipal solid waste management [10]. One of these barriers is the absence of a formal recycling platform. Recycling is viewed as a fundamental aspect in sustainable waste management and mainly as pro-environmental consumer behavior; because of this sustainability and recycling behavior are intertwined [11]. As sustainability and recycling behavior are interrelated, it is relevant to examine households' perception of monetary incentives as well as the key drivers or motivational factors for sustainable waste recycling in Nigeria.

Since a formal advocacy platform for the recycling of municipal solid waste is yet to be launched in Nigeria, individuals and corporate bodies are promoting and establishing avenues for increasing the recovery of recyclable items. An instance is the University of Lagos Recycling Project, which provides a venue for returning plastic bottles and in turn monetary rewards are given to the recyclers. Another instance is Wecyclers, a social enterprise involved in the collection of recyclable items from low-income areas in Lagos state using an incentive-based model [12].

Different scholars have conducted recycling related studies for solid waste management in Nigeria $[3,7,13,14]$. Research findings revealed that environmental preservation is the highest ranked benefit of recycling among the four elements of perceptions about recycling benefits to households in Kaduna, Northern Nigeria; namely environmental preservation, resource and cost conservation, monetary reward, and environmental awareness [7]. The study noted that environmental awareness is a prelude to environmental preservation and monetary reward. It considered the analysis of environmental awareness in three sub-components: ease of waste disposal, nurturing values and awareness, and inculcating environmental sanitation among young people. This study affirms the assumption that financial incentives are one of the most important factors for promoting the recycling of municipal solid waste at household level in Nigeria.

Findings from a study on the analysis of barrier and success factors affecting the adoption of sustainable management of municipal solid waste in Abuja, the capital city of Nigeria, point towards sustained public education on waste prevention and reuse as being the solution to waste problems in Nigeria [10]. This has become necessary owing to the growing population of the city. Underpinning this result is an economic factor. A segment of the population that engages in or participates in the recycling chain derives some utility in extending the useful life of the waste materials. Putting in place financial incentives for recycling, among other drivers, will be pivotal for Nigeria as the country transitions from a predominance of informal actors to full participation of formal actors in waste management. Although informal actors in the waste management chain play a vital role in championing reduce, reuse, and recycling in Nigeria, the participation of formal actors with accompanying institutionalization and legislation will fast track behavioral change-particularly waste separation at the source. In addition, 
the inability of the informal actors to muster the required human capacity, as well as the financial, technological, and other resources necessary for efficient waste management is a major disadvantage. Informal waste management continues to be bogged down by problems such as the occupational and public health hazards caused by poor waste processing, inefficiency in handling high volumes of waste in a growing city, uncontrolled pollutant flow, and child labor among others [15].

The management of solid waste is an enormous challenge in Nigeria particularly in urban areas with increasing populations. For instance, Lagos State which is the most populous and one of the most industrialized cities in the country, albeit having the smallest land area, produces approximately 11 thousand tons of waste per day $[3,16]$. Waste generation rates differ from city to city based on diverse factors such as population size, the level of urbanization, the level of development, and social and economic activities. Findings from a survey conducted in parts of Markurdi, the capital of Benue State in Central Nigeria, showed that waste generation rates for households were $0.54 \mathrm{~kg} / \mathrm{capita} /$ day [17]. A study on household waste composition and quantities in Abuja revealed that the average daily per capita household waste production was $0.634 \mathrm{~kg} / \mathrm{capita} /$ day [18]. These all point to the problem of increasing waste generation in Nigeria.

The numerous problems associated with poor state of solid waste management in Nigeria have been discussed in different studies [10,19-22]. The problems include: unfavorable economic conditions, poor institutional arrangements, the lack of the necessary legislative backing and poor implementation of waste management laws, as well as other technical and operational constraints. Another major constraint, which affects the level of recycling in Nigeria is the lack of a framework for extended producer responsibility (EPR). Nigeria currently does not have an EPR legislation in place, which implies that manufacturers of products are not obligated nor involved in any voluntary scheme that promotes reuse and recycling

Despite the massive problems affecting waste management in Nigeria, the country has the capacity and there exist incentives to adopt effective recycling practices similar to those that have been adopted in most developed countries. A review on plastic recycling based on previous studies carried out in different countries concluded that economic, environmental, and social factors are key to driving the sustainable development of recycling systems [23]. Economic, environmental, and social factors will remain crucial in driving Nigeria towards adopting sustainable recycling systems for municipal solid waste. A study conducted by [24] assessed the adoption of energy recycling within the European Union as part of the circular economy approach for sustainably managing municipal solid waste.

\section{Materials and Methods}

\subsection{Data Collection}

The study was conducted using primary sources of data. Primary data were collected through closed-ended questionnaires on the perception of financial incentives for households in endorsing sustainable waste recycling in Nigeria. The first section of the questionnaire included questions that focused on the personal characteristics of respondents, while subsequent sections of the questionnaire included questions that focused on the role of financial incentives for recycling from the consumers' perspective and drivers for household willingness to recycle including both intrinsic and extrinsic factors. The questionnaire included nominal and ordinal variables. The ordinal variables were ranked on a five point Likert Scale namely: strongly agree $=1$; agree $=2$; undecided $=3$; disagree $=4$; strongly disagree $=5$. Questions regarding the perception of financial incentives as a driver for recycling were considered in an itemized list on the roles of financial incentives on a five point Likert Scale. These statements viewed roles such as stimulating knowledge for the recycling of waste, waste reduction and increased recycling, consideration for behavioral change, critical motivational factors for recycling, influencing the desire to recycle waste, present positive trends for recycling waste, the tangible benefits for recycling waste, feasible goals of recycling waste, a sustainable approach for recycling waste, promotion of awareness for recycling waste, and promotion of recycling best practices. 
In addition, questions covering drivers for willingness to recycle were considered in an itemized list reflecting drivers encompassing environmental risks, behavioral economics, resource value, economic benefit, convenience, knowledge, legislation, and belief. Answers were provided to the questions as respondents were asked to indicate " $\mathrm{X}$ " for the response best applicable to the statements. The survey was conducted in summer, 2017.

\subsection{Population and Sampling Technique}

The projected population of the Shomolu Local Government Area as of 2015 was 1,361,100 [25], this included 967 households distributed within eight wards [26]. The Shomolu Local Government is one of the 16 Local Governments in Metropolitan Lagos. It has a land area of $14.6 \mathrm{~km}$ square and is part of the Ikeja division of Lagos State, Nigeria. To the north it shares boundary with Kosofe, and to the south it shares boundary with the Lagos Mainland Local Government Area (LGA). To the East it shares boundary with the Mushin Local Government Area.

It is a major site of commercial printing activities in Lagos State. It is predominantly a residential suburb with huge problems related to inadequate sanitation, overcrowding, and poor housing.

Using a door-to-door approach for the survey, 135 households were administered questionnaires. The study employed a stratified random technique. This approach guaranteed precision of the samples by avoiding sampling error. The Shomolu Local Government Area was divided into stratums of eight political wards, thereafter, households were randomly approached from each political ward. To ensure a good representation of samples, efforts were made to guarantee a wide geographic spread of the households selected. Efforts were also made to capture households belonging to different socio-economic groups. The survey elicited information only from the heads of households. By means of a sample size calculator, sample size was determined by inputting a projected population of $1,361,100$ [25] at a confidence level of $95 \%$ and confidence interval of $8 \%$.

\subsection{Data Analysis}

The data collected were analyzed using the statistical package for the Social Science (SPSS) software. Primary data for the study were analyzed using descriptive (cross tabulation, frequency, percentage, mean, and standard deviation) and inferential statistics (Spearman's rank-order correlation). The unit of analysis for the study was household level.

\section{Results and Discussion}

\subsection{Descriptive Statistics}

\subsubsection{Households' Perception of Financial Incentives for Recycling}

The empirical results in Table 1 depict households' perception of financial incentives for recycling from a scale of strongly agree (1) to strongly disagree (5).

More than one-third of the respondents (40.7\%) strongly agreed that financial incentives stimulate knowledge for the recycling of waste. About half of the respondents $(46.7 \%)$ agreed that financial incentives play a significant role in reducing waste and increasing recycling. More than half of the respondents $(51.9 \%)$ agreed that a financial incentives influence the desire to recycle waste. A smaller proportion of $12.6 \%$ of the respondents were undecided about financial incentives being feasible for the goal of recycling waste. Furthermore, none of the respondents $(0.0 \%)$ strongly disagreed that financial incentives present positive trends for recycling waste. Less than one-tenth of the respondents $(8.1 \%)$ disagreed about financial incentives being a sustainable approach for recycling waste.

The mean scores of all items that measure households' perception of financial incentives for recycling ranged from 1.87 to 2.11. This infers that in the Somolu Local Government Area of Lagos State, financial incentives for recycling municipal solid waste from a household perspective plays 
a significant role in reducing waste and increasing recycling. Similarly, the minor role of financial incentives for managing municipal solid waste is a tangible benefit derivable from recycling waste.

The mean scores of all items that measure households' perception of financial incentives for recycling fell below the set mid-point (2.50). This finding infers that financial incentives for recycling are important for reducing municipal solid waste.

Table 1. Descriptive statistics of households' perception of financial incentives for recycling.

\begin{tabular}{|c|c|c|c|c|c|c|c|}
\hline Statements & Strongly Agree & Agree & Undecided & Disagree & Strongly Disagree & Mean & Standard Deviation \\
\hline PFIR 1 & $55(40.7)$ & $60(44.4)$ & $9(6.7)$ & $8(5.9)$ & $3(2.2)$ & 1.87 & 0.987 \\
\hline PFIR 2 & $59(43.7)$ & $63(46.7)$ & $2(1.5)$ & $8(5.9)$ & $3(2.2)$ & 1.76 & 0.916 \\
\hline PFIR 3 & $41(30.4)$ & $58(43.0)$ & $19(14.1)$ & $16(11.9)$ & $1(0.7)$ & 2.10 & 0.992 \\
\hline PFIR 4 & $42(31.1)$ & $63(46.7)$ & 18(13.3) & $12(8.9)$ & $0(0.0)$ & 2.00 & 0.898 \\
\hline PFIR 5 & $42(31.1)$ & $70(51.9)$ & $13(9.6)$ & $10(7.4)$ & $0(0.0)$ & 1.93 & 0.839 \\
\hline PFIR 6 & $40(29.6)$ & $71(52.6)$ & $16(11.9)$ & $8(5.9)$ & $0(0.0)$ & 1.94 & 0.808 \\
\hline PFIR 7 & $36(26.7)$ & $67(49.3)$ & $15(11.1)$ & $14(10.4)$ & $3(2.2)$ & 2.11 & 0.998 \\
\hline PFIR 8 & $38(28.1)$ & $69(51.1)$ & $17(12.6)$ & $10(7.4)$ & $1(0.7)$ & 2.01 & 0.881 \\
\hline PFIR 9 & $39(28.9)$ & $69(51.1)$ & $11(8.1)$ & $11(8.1)$ & $5(3.7)$ & 2.07 & 1.016 \\
\hline PFIR 10 & $50(37.0)$ & 69(51.1.) & 10(7.4) & $5(3.7)$ & $1(0.7)$ & 1.80 & 0.790 \\
\hline PFIR 11 & $43(31.9)$ & $68(50.4)$ & 12(8.9) & $11(8.1)$ & $1(0.7)$ & 1.96 & 0.897 \\
\hline Variable & \multicolumn{7}{|c|}{ Definition } \\
\hline PFIR 1 & \multicolumn{7}{|c|}{ Financial incentives stimulate knowledge for the recycling of waste } \\
\hline PFIR 2 & \multicolumn{7}{|c|}{ Financial incentives play a significant role in reducing waste and increasing recycling } \\
\hline PFIR 3 & \multicolumn{7}{|c|}{ Financial incentives are a consideration for behavioral change } \\
\hline PFIR 4 & \multicolumn{7}{|c|}{ Financial incentives are a critical motivational factor for recycling } \\
\hline PFIR 5 & \multicolumn{7}{|c|}{ Financial incentives influence the desire to recycle waste } \\
\hline PFIR 6 & \multicolumn{7}{|c|}{ Financial incentives present positive trends for recycling waste } \\
\hline PFIR 7 & \multicolumn{7}{|c|}{ Financial incentives are a tangible benefit from recycling waste } \\
\hline PFIR 8 & \multicolumn{7}{|c|}{ Financial incentives are feasible for the goal of recycling waste } \\
\hline PFIR 9 & \multicolumn{7}{|c|}{ Financial incentives are a sustainable approach for recycling waste } \\
\hline PFIR 10 & \multicolumn{7}{|c|}{ Financial incentives promote awareness for recycling waste } \\
\hline PFIR 11 & \multicolumn{7}{|c|}{ Financial incentives promote the best recycling practices } \\
\hline
\end{tabular}

\subsubsection{Drivers for a Households' Willingness to Recycle}

The empirical results in Table 2 show the drivers for a households' willingness to recycle municipal solid waste on a five point Likert scale from strongly agree (1) to strongly disagree (5).

More than one-third of the respondents (43.0\%) strongly agreed that they would drop recyclable materials at designated points considering its detrimental environmental impact. More than half of the respondents (57.8\%) agreed that they would drop recyclable materials at designated points because of the stipulated policies and regulations. Less than one-tenth of the respondents $(8.9 \%)$ were undecided about dropping recyclable materials at designated points on account of the associated financial incentives. Just fewer than twenty percent $(17.8 \%)$ of the respondents disagreed with dropping recyclable materials at designated points because of the proximity of recycling facilities. None of the respondents $(0.0 \%)$ strongly disagreed with dropping recyclable materials at designated points because of their belief in the benefit of recycling.

The mean scores of all items that measure drivers for a households' willingness to recycle municipal solid waste ranged from 1.84 to 2.35 . This infers that the most important driver for a households' willingness to recycle municipal solid waste is the detrimental environmental impacts in the Somolu Local Government Area, Lagos state. This is in line with the study by Reference [27] which found that environmental benefits are one of the important factors for promoting consumer participation in waste management. Likewise, the least important driver is proximity to recycling facilities.

The mean scores of all items that measure drivers for a households' willingness to recycle municipal solid waste fell below the set mid-point (2.50). This finding suggests that drivers are indispensable for a households' willingness to recycle municipal solid waste in the Somolu Local government Area, Lagos State. 
Table 2. Descriptive statistics of drivers for a households' willingness to recycle.

\begin{tabular}{|c|c|c|c|c|c|c|c|}
\hline Statements & Strongly Agree & Agree & Undecided & Disagree & Strongly Disagree & Mean & Standard Deviation \\
\hline DFWTR 1 & $58(43.0)$ & $56(41.5)$ & $8(5.9)$ & $10(7.4)$ & $3(2.2)$ & 1.84 & 0.984 \\
\hline DFWTR 2 & $43(31.9)$ & $61(45.2)$ & $12(8.9)$ & $17(12.6)$ & $2(1.5)$ & 2.08 & 1.037 \\
\hline DFWTR 3 & $38(28.1)$ & $71(52.6)$ & $9(6.7)$ & 16(11.9) & $1(0.7)$ & 2.04 & 0.95 \\
\hline DFWTR 5 & $34(25.2)$ & $75(55.6)$ & 15(11.1) & $24(17.8)$ & $6(4.4)$ & 2.35 & 1.167 \\
\hline DFWTR 6 & $34(25.2)$ & $75(55.6)$ & $11(8.1)$ & $9(6.7)$ & $6(4.4)$ & 2.1 & 0.999 \\
\hline DFWTR 7 & $29(21.5)$ & $78(57.8)$ & $13(9.6)$ & $12(8.9)$ & $3(2.2)$ & 2.13 & 0.926 \\
\hline DFWTR 8 & $53(39.3)$ & $58(43.0)$ & $13(9.6)$ & $11(8.1 .0)$ & $0(0.0)$ & 1.87 & 0.896 \\
\hline Variable & \multicolumn{7}{|c|}{ Definition } \\
\hline DFWTR 1 & \multirow{2}{*}{\multicolumn{7}{|c|}{$\begin{array}{l}\text { I will drop recyclable materials at designated points considering its detrimental environmental impac } \\
\text { I will drop recyclable materials at designated points due to my culture of stewardship, conservation, } \\
\text { and preservation }\end{array}$}} \\
\hline DFWTR 2 & & & & & & & \\
\hline DFWTR 3 & \multicolumn{7}{|c|}{ I will drop recyclable materials at designated points because it is valuable } \\
\hline DFWTR 4 & \multicolumn{7}{|c|}{ I will drop recyclable materials at designated points relative to the associated financial incentives } \\
\hline DFWTR 5 & \multicolumn{7}{|c|}{ I will drop recyclable materials at designated points due to the proximity of recycling facilities. } \\
\hline DFWTR 6 & \multicolumn{7}{|c|}{ I will drop recyclable materials at designated points relative to the extent of the information provided } \\
\hline DFWTR 7 & \multicolumn{7}{|c|}{ I will drop recyclable materials at designated points because of the stipulated policies and regulations } \\
\hline DFWTR 8 & \multicolumn{7}{|c|}{ I will drop recyclable materials at designated points because of my belief in the benefit of recycling } \\
\hline
\end{tabular}

Percentages are in parenthesis.

\subsection{Inferential Statistic}

\section{Spearman's Rank Correlation}

A Spearman's rank-order correlation (Table 3) was used to investigate the direction and strength of the relationship between the perception of financial incentives for recycling and the drivers for recycling. The correlation coefficient of 0.440 indicates that a moderate to positive relationship exists between households' perception of financial incentives for recycling and drivers for recycling. This infers that as the perception of financial incentives for recycling increases, the drivers for recycling increase, and as the drivers for recycling increase, the perception of financial incentives for recycling increases, respectively. The probability value of less than 0.001 , as compared to an alpha value of 0.01 , proves that there is a significant relationship between the perception of the role of financial incentives for recycling municipal solid waste and the drivers for household willingness to recycle, as the P-value is less than $\alpha$ value.

Table 3. Spearman's rank-order correlation between perception of financial incentives and drivers for recycling.

\begin{tabular}{lcccc}
\hline & & PFI & DFR \\
\cline { 3 - 4 } & \multirow{3}{*}{ PFIR } & Correlation Coefficient & 1.000 & $0.440^{* *}$ \\
& & Sig. (two-tailed) & & 0.000 \\
Spearman's Rho & $\mathrm{N}$ & 135 & 135 \\
& & Correlation Coefficient & $0.440^{* *}$ & 1.000 \\
& DFWTR & Sig. (two-tailed) & 0.000 & \\
& & $\mathrm{~N}$ & 135 & 135 \\
\hline
\end{tabular}

** Correlation is significant at the 0.01 level (two-tailed). PFIR-Perception of financial incentives for recycling, DFWTR-Drivers for a households' willingness to recycle, Rho (rank correlation coefficient).

\subsection{Cronbach Alpha}

Cronbach alpha is a reliability test that measures the internal consistency of a scale [28]. The Cronbach alpha for household perception of financial incentives for recycling was 0.776 and willingness to recycle was 0.627 . This infers that the respondents' perception of financial incentives for recycling as well as willingness to recycle are consistent. According to Reference [29], "alpha greater than 0.90 most likely indicate unnecessary redundancy rather than a desirable internal 
consistency". The usefulness of this result to the study is to ensure accuracy and add validity to the interpretation of data.

\section{Conclusions and Recommendations}

Nigeria needs to make the transition to a sustainable waste management approach. A key step towards this transition is the adoption of recycling for the management of municipal solid waste, which has been increasing as the population in urban centers in Nigeria increases. The adoption of a recycling approach in waste management will help to reduce the amount of waste that goes to dumps sites, and constitutes health and environmental hazards. The adoption of recycling will also contribute to reducing the energy used in production as well as contributing to enhancing the economy. This paper examined the drivers for the adoption of recycling in Lagos, Nigeria. The study focused on assessing the response of households to financial incentives as a motivation for adopting recycling. Understanding the perception of the household has become critical in designing a set of policies and tools for incentivizing and promoting a recycling culture in Nigeria. Our findings indicate that households will respond to financial incentives as well as an increased understanding of the detrimental impact of inefficient waste management methods, because of this the government and stakeholders must implement keys steps including: adopting the extended producer responsibility (EPR) method, reverse vending options, among other approaches, to work towards promoting a recycling culture among the citizens and resident of Nigeria. The country also needs to move forward in the adoption of a circular economy that prioritizes energy recycling as an approach for sustainably managing municipal solid waste.

Acknowledgments: The author appreciates the support of the ICT Unit of the University of Vaasa, particularly for providing the Analytical Software used for analysing the data. The effort of Nelson Abila in reviewing several drafts of the paper is equally appreciated.

Conflicts of Interest: The author declares no conflict of interest.

\section{References}

1. Refsgaard, K.; Magnussen, K. Household behaviour and attitudes with respect to recycling food waste-Experiences from focus groups. J. Environ. Manag. 2009, 90, 760-771. [CrossRef] [PubMed]

2. Akil, A.M.; Foziah, J.; Ho, C.S. The effects of Socio-economic influences on households' recycling behaviour in Iskander, Malysia. Procedia-Soc. Behav. Sci. 2015, 202, 124-134. [CrossRef]

3. Kofoworola, O.F. Recovery and recycling practices in municipal solid waste management in Lagos, Nigeria. Waste Manag. 2007, 27, 1139-1143. [CrossRef] [PubMed]

4. Shaw, P.J.; Maynard, S.J. The potential of financial incentives to enhance householders' kerbicide recycling behaviour. Waste Manag. 2008, 28, 1732-1741. [CrossRef] [PubMed]

5. Timlett, R.E.; Williams, I.D. Public participation and recycling performance in England: A comparison of tools for behavioural change. Resour. Conserv. Recycl. 2008, 52, 622-634. [CrossRef]

6. Adeniran, A.E.; Nubi, A.T.; Adelopo, A.O. Solid waste generation and characterization in the University of Lagos for a sustainable waste Management. Waste Manag. 2017, 67, 3-10. [CrossRef] [PubMed]

7. Abd Razack, N.T.A.; Medayese, S.O.; Shaibu, S.I.; Adeleye, B.M. Habits and benefits of recycling solid waste among households in Kaduna, North West Nigeria. Sustain. Cities Soc. 2017, 28, 297-306. [CrossRef]

8. Amini, F.; Ahmad, J.; Ambali, A.R. The influence of reward and penalty on households recycling intention. APCBEE Procedia 2014, 10, 187-192. [CrossRef]

9. Miliute-Plepiene, J.; Hage, O.; Plepys, A.; Reipas, A. What motivates households recycling behaviour in recycling schemes of different maturity? Lessons from Luthuania and Sweden. Resour. Conserv. Recycl. 2016, 113, 40-52. [CrossRef]

10. Ezeah, C.; Roberts, C.L. Analysis of barriers and success factors affecting the adoption of sustainable management of municipal solid waste in Nigeria. J. Environ. Manag. 2012, 103, 9-14. [CrossRef] [PubMed]

11. Schill, M.; Shaw, D. Recycling today, sustainability tomorrow: Effects of psychological distance on behavioural practice. Eur. Manag. J. 2016, 34, 349-362. [CrossRef] 
12. Wecyclers. Available online: http:/ / wecyclers.com/ (accessed on 3 November 2017).

13. Adewole, T.A. Waste management towards sustainable development in Nigeria. A case study of Lagos State. Int. Non-Govtal. Organ. J. 2009, 4, 173-179.

14. Agunwamba, J.C.; Ukpai, O.K.; Onyebuichi, I.C. Solid waste management in Onitsha, Nigeria. J. Waste Manag. Res. 1998, 16, 23-31. [CrossRef]

15. Velis, C.A.; Wilson, D.C.; Rocca, O.; Smith, S.R.; Mavropoulos, A.; Cheeseman, C.R. An analytical framework and tool (InteRa) for integrating the informal sector in waste and resource management systems in developing countries. Waste Manag. Res. 2012, 30, 43-66. [CrossRef] [PubMed]

16. Solomon, U.U. The state of solid waste management in Nigeria. Waste Manag. 2009, 29, 2787-2790. [CrossRef] [PubMed]

17. Sha Ato, R.; Aboho, S.Y.; Oketunde, F.O.; Eneji, I.S.; Unazi, G.; Agwa, S. Survey of solid waste generation and composition in a rapidly growing urban area in Central Nigeria. Waste Manag. 2007, 27, 352-358. [CrossRef] [PubMed]

18. Ogwueleka, T.C. Survey of household waste composition and quantities in Abuja, Nigeria. Resour. Conserv. Recycl. 2013, 77, 52-60. [CrossRef]

19. Abila, B.; Kantola, J. Proposed solutions in municipal solid-waste management. Int. J. Environ. Waste Manag. 2017, 19, 297-317. [CrossRef]

20. Okot-Okumu, J.; Nyenje, R. Municipal solid waste management under decentralisation in Uganda. Habitat Int. 2012, 35, 537-543. [CrossRef]

21. Oguntoyinbo, O.O. Informal waste management system in Nigeria and barriers to an inclusive modern waste management system: A review. Public Health 2012, 126, 441-447. [CrossRef] [PubMed]

22. Imam, A.; Mohammed, B.; Wilson, D.E.; Cheeseman, C.R. Solid waste management in Abuja, Nigeria. Waste Manag. 2008, 28, 468-472. [CrossRef] [PubMed]

23. Mwanzaa, B.G.; Mbohwab, C. Drivers to Sustainable Plastic Solid Waste Recycling: A Review. Procedia Manuf. 2017, 8, 649-656. [CrossRef]

24. Malinauskaite, J.; Jouhara, H.; Czajczynska, H.; Stanchev, P.; Katsou, E.; Rostkowski, P.; Thorne, R.J.; Colon, J.; Ponsa, S.; Al-Mansour, F.; et al. Municipal solid waste management and waste-to-energy in the context of a circular economy and energy recycling in Europe. Energy 2017, 141, 2013-2044. [CrossRef]

25. City Population. Available online: https://www.citypopulation.de/php/nigeria-metrolagos.php?cityid= NGA025019 (accessed on 28 October 2017).

26. Lagos Bereau of Statistics. Available online: http://mepb.lagosstate.gov.ng/wp-content/uploads/sites/29/ 2017/01/HOUSEHOLD-SURVEY-2006-REPORT-1.pdf (accessed on 28 October 2017).

27. Owusu, V.; Afjei-Addo, E.; Sundberg, C. Do economic incentives affect attitude to solid waste source separation? Evidence from Ghana. Resourc. Conserv. Recycl. 2013, 78, 115-123. [CrossRef]

28. Taber, K.S. The use of Cronbach alpha when developing and reporting research instruments in Science Education. Res. Sci. Educ. 2017, 1-24. [CrossRef]

29. Streiner, D.L. Starting at the beginning: An introduction to coefficient alpha and internal consistency. J. Pers. Assess. 2003, 80, 99-103. [CrossRef] [PubMed]

(C) 2018 by the author. Licensee MDPI, Basel, Switzerland. This article is an open access article distributed under the terms and conditions of the Creative Commons Attribution (CC BY) license (http://creativecommons.org/licenses/by/4.0/). 